\title{
Carbon Dots as Sensing Layer for Printed Humidity and Temperature Sensors
}

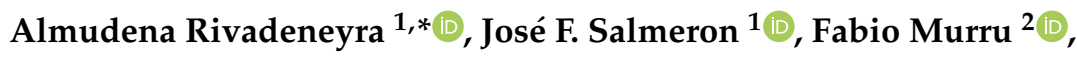 \\ Alejandro Lapresta-Fernández ${ }^{2} \mathbb{B}$, Noel Rodríguez ${ }^{1}{ }^{\mathbb{C}}$, Luis Fermín Capitan-Vallvey ${ }^{2}{ }^{\mathbb{B}}$, \\ Diego P. Morales ${ }^{1}\left(\mathbb{D}\right.$ and Alfonso Salinas-Castillo ${ }^{2} \mathbb{D}$ \\ 1 Department of Electronics and Computer Technology, University of Granada, 18010 Granada, Spain; \\ jfsalmeron@ugr.es (J.F.S.); noel@ugr.es (N.R.); diegopm@ugr.es (D.P.M.) \\ 2 Department of Analytical Chemistry, University of Granada, 18010 Granada, Spain; \\ fmurru@correo.ugr.es (F.M.); lapresta@ugr.es (A.L.-F.); lcapitan@ugr.es (L.F.C.-V.); alfonsos@ugr.es (A.S.-C.) \\ * Correspondence: arivadeneyra@ugr.es; Tel.: +34-958-248-996
}

Received: 30 November 2020; Accepted: 5 December 2020; Published: 7 December 2020 updates

\begin{abstract}
This work presents an innovative application of carbon dots (Cdots) nanoparticles as sensing layer for relative humidity detection. The developed sensor is based on interdigitated capacitive electrodes screen printed on a flexible transparent polyethylene terephthalate (PET) film. Cdots are deposited on top of these electrodes. An exhaustive characterization of the nanoparticles has been conducted along with the fabrication of the sensor structure. The accompanied experiments give all the sensibility to the Cdots, showing its dependence with temperature and exciting frequency. To the best of our knowledge, this work paves the path to the use of these kind of nanoparticles in printed flexible capacitive sensors aimed to be employed in the continuously expanding Internet of Things ecosystem.
\end{abstract}

Keywords: capacitive sensors; moisture content; nanomaterials; screen printing; printed electronics

\section{Introduction}

The increasing demand in sensors and actuators in recent decades has motivated the research of new sensing nanomaterials, which fulfil the desired requirements such as cost-effective production, high sensitivity, and high selectivity to the parameter of interest, among other characteristics [1]. Furthermore, though the sensing material improvement is of principal interest not least is the selection of the substrate that supports it. This selection determines the integration of the sensor with the environment where the magnitude to measure must be acquired. Ideally, the inclusion of sensor systems must be transparent to the controlled processes and above all, it should not influence the design of the process or system to be controlled.

In this context, the development of relative humidity (RH) sensors attracted considerable attention given their importance for various processes in the food industry and industrial processes [2-5]. In particular, the interdigitated electrode (IDE) has been extensively investigated to detect capacitive humidity sensors [6-8]. Many materials have been used to manufacture flexible relative humidity sensors in IDE systems, such as carbon nanotubes (CNTs) [9], metal and organic frameworks (MOFs) [10], and different polymers or oxides [11-13].

In this sense, nanomaterials (metal nanoparticles, semiconductor quantum dots, carbon dots, nanotubes, and nanocrystals) can be used as novel sensing elements and they allow us to build devices much smaller than before. There are many examples in the literature where this kind of materials are employed for different sensing applications. For example, CNTs and graphene derivates have been utilized for gas [14-16], temperature [17,18], and relative humidity (RH) sensing [12,19]. They offer 
high sensitivity and flexibility to the sensor but they lack of selectivity: they response to almost everything [20]. Other widely used nanomaterials are metal nanoparticles, which have been used for not only electrodes [21] but also together with CNTs to tune their selectivity [22,23]. Recently, new nanoparticles called carbon dots have emerged and attracted growing interest in chemistry, physics, and materials science. Carbon dots (Cdots) exhibit excellent properties, which include aqueous solubility, good electronic conductivity, low toxicity, and biocompatibility [24]. They can be synthesized using a simple, cost-effective, and environmentally friendly method at large scale. Although these Cdots-based materials hold great promise in bioimaging, drug delivery, sensors, photocatalysis, and optoelectronics [25], much work is still necessary to explore the full potentials of these nanomaterials in the development of advanced smart sensors, a new avenue for creating simple, selective, and non-invasive real-time analysis, as they can satisfy the growing demand for rapid and cost-effective quantitation [26].

In this work, we demonstrate the potential use of Cdots as sensing layer for capacitive RH and temperature sensors, contrary to other works where the use of Cdots is limited to resistive sensors [27-29]. The designed sensors are manufactured on a flexible substrate by means of printed electronics (PE), which allows their integration in almost any device or artefact, enabling its pervasiveness (understood as the ability to be integrated into any element of the environment), and a desired feature for the well-known Internet of Things (IoT) ecosystem. Indeed, thanks to PE, the sensors fulfil most of the desired features of the IoT paradigm, where each physical entity can be connected to its environment and share parameters of its surroundings and self-status, and therefore, they will contain more than one sensor. For these huge amount of needed devices (it is expected by 2020 to have more than 75 billion connected things $[1,30])$, it is mandatory to achieve cost-effective and large-scale manufacturing. Moreover, other desirable features are conformability (for adapting the electronics to the surfaces shapes) and environmental friendliness (for the reduction of generated wastes during the whole product life). All these features can be achieved by using PE [31,32]. The sensor described in this work corresponds to such devices incorporating a novel sensing element: a Cdots-based layer. It is the first time that their electrical properties towards environmental conditions have been explored to the best of our knowledge. We have also performed such analysis over frequency in order to gain a better insight of its response and try to exploit it better as in previous works $[9,33]$.

The exhaustive presentation of the work introduced in this manuscript is structured in the following sections. Section 2 presents all the materials and methods used for developing the RH sensor: from the tools and instruments for the synthesis of the carbon dots to the fabrication and deposition technologies for the interdigitated electrode (IDE) capacitive sensor. The document continues in Section 3 showing the results obtained from de devices under test (DUT), describing the conducted experiments. A detailed discussion of these results shows the skills of these $\mathrm{RH}$ sensors indicating its dependence and behavior with temperature changes. Finally, Section 4 contains the conclusion of this work where its strengths are remarked.

\section{Materials and Methods}

\subsection{Carbon Dots Synthesis}

\subsubsection{Synthesis of Carbon Dots}

The Cdots were prepared according to the procedure described by Salinas-Castillo et al. [34,35]. Rapid procedure with a dissolved citric acid and polyethyleneimine (PEI) in water, then, it was placed in microwave oven and heated at $180^{\circ} \mathrm{C}$ for $5 \mathrm{~min}$ at a power of $850 \mathrm{~W}$. The solution was dialyzed using spectra7pro dialysis membrane $1 \mathrm{KDa}$ cut-off. The solution was characterized by several techniques and obtained results agree with previous works. 


\subsubsection{Instrumentation}

Microwave Milestone MicroSYNTH (Milestone Srl, Sorisole (BG), Italy) was used for synthesis. XRD was carried out at the Center of Scientific Instrumentation (University of Granada, Granada, Spain) on an EA 1108 model Fisons-Carlo Erba analyzer (Egelsbach, Germany). High-resolution transmission electron microscopy (HR-TEM) images were obtained from a FEI TITAN G2 60-300 field-emission instrument, equipped with a HAADF detector, the samples were prepared at room temperature in air by the deposition of a drop of aqueous solution of CNDs on a commercial $400 \mu \mathrm{m}$ mesh carbon Cu-grid.

Fourier transform infrared (FTIR) spectra were obtained using a PerkinElmer FT-IR Spectrum Two spectrometer (PerkinElmer, Waltham, MA, USA). The X-ray diffraction (XRD) was carried out at the Centre of Scientific Instrumentation (University of Granada) on a Fisons-Carlo Erba analyzer model EA 1108. X-ray photoelectron spectroscopy (XPS) analyses were carried out at the Centre of Scientific Instrumentation (University of Granada), with a Kratos Axis Ultra-DLD (Kratos Analytical Ltd., Manchester, UK).

\subsection{Sensor Fabrication}

The sensors were fabricated on the transparent (polyeth)ylene ter(ephthalate) (PET) film with $125 \mu \mathrm{m}$. First, the interdigitated electrodes (IDEs) were screen printed with manual screen printer Nino (Coruna Printed Electronics GmbH, Bettwil, Switzerland) using a silver conductive paste (1010 from Loctite, Düsseldorf, Germany). The paste consists of $68 \pm 2 \%$ silver particles. The screen mesh density was $165 \mathrm{~T} / \mathrm{cm}$. After depositing the electrodes, the samples were dried in an oven (Memmbert UF55, Memmert GmbH + Co.KG, Schwabach, Germany) at $60{ }^{\circ} \mathrm{C}$ for $60 \mathrm{~min}$.

The NP were dispersed in ethanol and left in ultrasonic bath for $1 \mathrm{~h}$. After that, they were drop-casted onto the electrodes and dried in a hotplate at $60^{\circ} \mathrm{C}$ for $10 \mathrm{~min}$. Figure 1 depicts a schematic of the sensor and a real picture of the device. The IDE structure is composed by 20 fingers per electrode of $2 \mathrm{~mm}$ length and $200 \mu \mathrm{m}$ width and spacing among consecutive fingers. The resulting thickness of the electrodes after the deposition of the CDots is $4.1 \pm 0.6 \mu \mathrm{m}$. The darker yellowish spots are accumulation of Cdots.

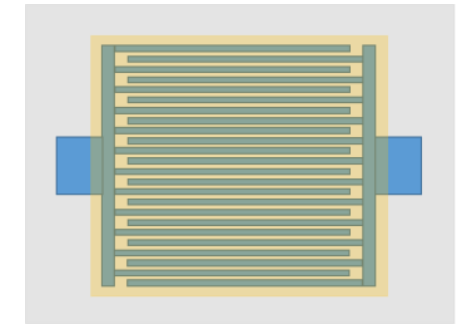

(a)

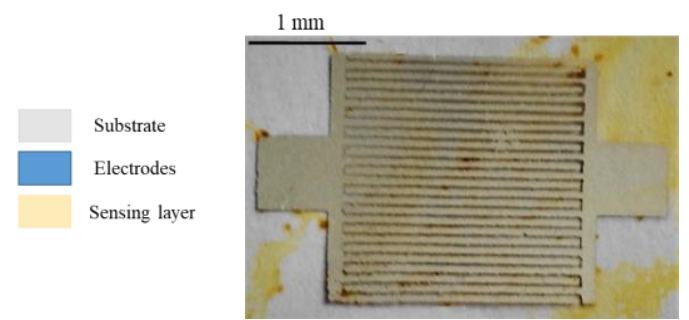

(b)

Figure 1. Schematic of the sensor (a) and real picture (b).

\subsection{Characterization}

The capacitance measurements were obtained using the E4990A impedance analyzer (from Keysight Technologies, Santa Rosa, CA, USA) with an impedance probe kit (42941A). The excitation voltage applied was $\mathrm{V}_{\mathrm{DC}}=0$ and $\mathrm{V}_{\mathrm{AC}}=500 \mathrm{mV}$ in all measurements and the frequency ranged from $1 \mathrm{kHz}$ to $10 \mathrm{MHz}$. A calibration was performed to compensate the parasitic elements, as the one described in [33]. The sensor was placed in a climatic chamber (VCL4006 from Vötsch Industrietechnik $\mathrm{GmbH}$, Balingen, Germany) with the temperature and humidity control.

For the RH sensing, the moisture content was ramped up in $10 \%$ steps and held for $1 \mathrm{~h}$ to ensure a stable value in the whole chamber volume. A similar approach was followed for the temperature sensing with $5{ }^{\circ} \mathrm{C}$ steps for $30 \mathrm{~min}$. The measurements were automated with the use of LabVIEW 2016. 
The thickness of the electrodes was measured with a Dektak XT ${ }^{\text {TM }}$ Stimulus Surface Profiling System (Bruker Corporation, Conventry, UK).

A custom bending setup as the one employed in [36] was used for the bending tests. The bending speed and minimum bending diameter were kept constant at $10 \mathrm{~mm} / \mathrm{s}$ and $1 \mathrm{~mm}$, respectively.

\section{Results and Discussion}

In this section, we first show the structural characterization of the Cdots followed by the electrical characterization of the fabricated device with respect to the moisture content at a fixed temperature. Later, we analyze the effect of temperature at different $\mathrm{RH}$ values.

\subsection{Characterization of Carbon Dots}

The size, morphology and structure of the Cdots were studied by high-resolution HR-TEM, EDX, XPS, FTIR, and XRD.

The HR-TEM image of Cdots shows that the Cdots are spherical with a low degree of the agglomeration. The particle size distribution histogram is presented in Figure 2a. The size of CDs is distributed in narrow range of 1-6 nm with an average particle size of $4 \mathrm{~nm}$, see Figure $2 \mathrm{~b}$. Elemental analyses were performed by EDX to disclose the composition of Cdots, showing that $\mathrm{C}, \mathrm{N}$, and $\mathrm{O}$ atoms are present on the composition of Cdots.
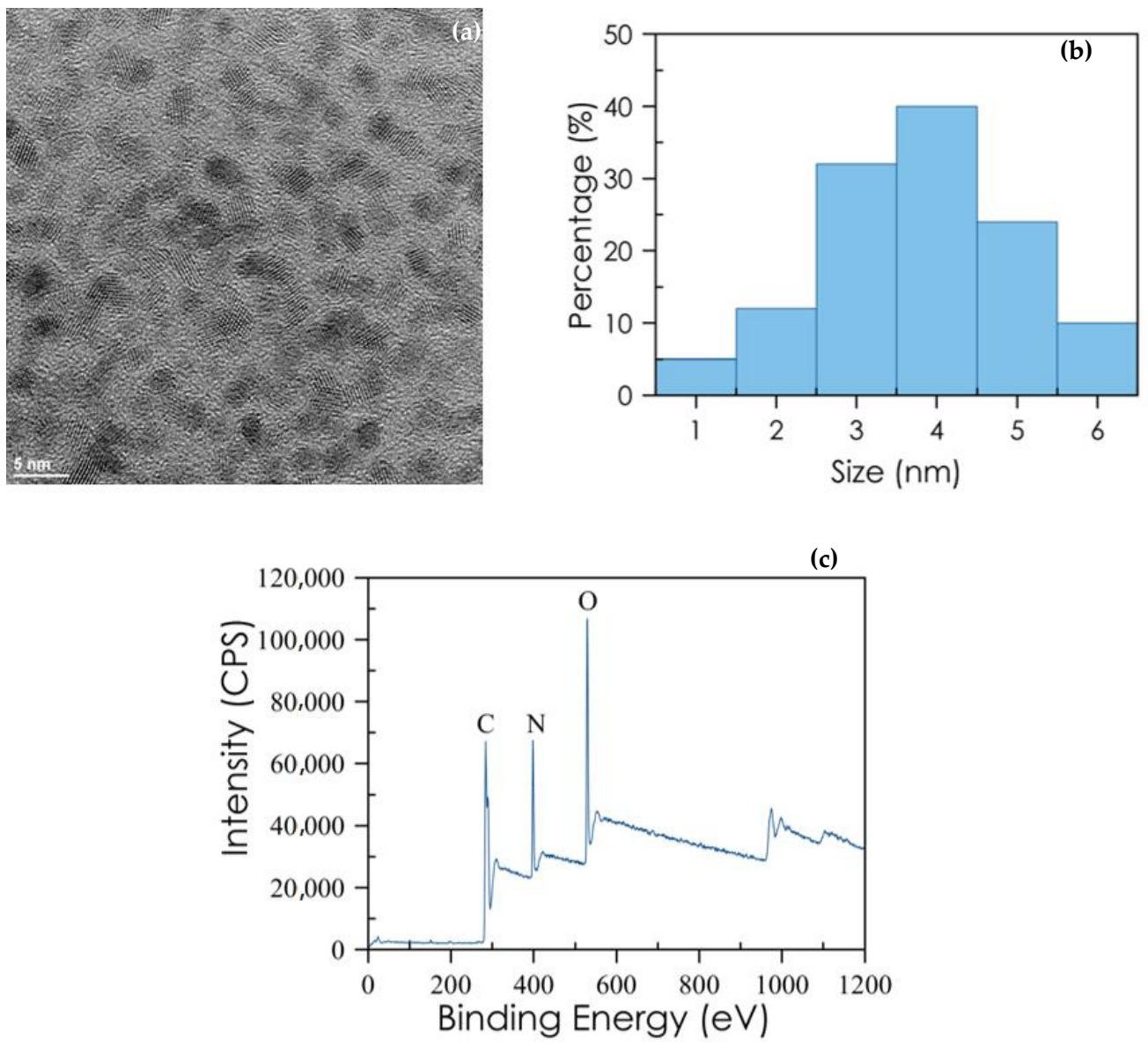

Figure 2. Characterization of the CDs. (a) HR-TEM image; (b) size distribution for CDs; (c) XPS spectra: C1s peak: $284 \mathrm{eV}$; N1s peak: $398 \mathrm{eV}$ and O1s peak: 530.

The FTIR spectrum of Cdots showed typical bands (COOH of $3440 \mathrm{~cm}^{-1}, \mathrm{NH}$ of $1585 \mathrm{~cm}^{-1}, \mathrm{CH}$ of 2950 and $2820 \mathrm{~cm}^{-1}, \mathrm{CN}$ of $1122 \mathrm{~cm}^{-1}$ ). Furthermore, the elemental analysis of the composition of the Cdots was performed by XPS surface analysis (Figure 2c). As expected, the obtained data for the 
elemental composition of Cdots indicate the presence of a carbon peak at about $284 \mathrm{eV}$, an oxygen peak at about $530 \mathrm{eV}$ and a nitrogen peak at about $398 \mathrm{eV}$. Additionally, the atomic quantification shows $69.37 \% \mathrm{C} 1 \mathrm{~s}, 16.62 \% \mathrm{O} 1 \mathrm{~s}$ and $14.02 \% \mathrm{~N} 1 \mathrm{~s}$ atoms. XRD pattern had a broad diffraction peak at $2 \Phi=20.5^{\circ}$, suggesting an amorphous material.

\subsection{Electrical Response to $R H$}

Before depositing the sensing layer, we measured a capacitive value of about $4 \mathrm{pF}$ at $100 \mathrm{kHz}$ at room conditions. We also characterized the silver electrodes on PET with the same RH swept and there was virtually no change in the capacitance over the frequency range selected (less than $3 \%$ in the whole range) [37]. Therefore, any variation in the response with respect to moisture content can be attributed to a change in the sensing layer.

Figure 3 present the response of the DUT (device under test) towards RH at different frequencies. The DUT shows a capacitive behavior with about $8.8 \mathrm{pF}$ measured at $100 \mathrm{kHz}$ and room conditions. The highest response to RH is found at the lowest frequency. Above $100 \mathrm{kHz}$ the capacitance changes less than $100 \mathrm{fF}$. Therefore, we have analyzed the response at $1 \mathrm{kHz}$ and $10 \mathrm{kHz}$ (see Figure 4). In terms of absolute response, the capacitance varies $2 \mathrm{pF}$ at $1 \mathrm{kHz}$ and $0.6 \mathrm{pF}$ at $10 \mathrm{kHz}$ from $20 \%$ to $85 \% \mathrm{RH}$. In terms of linearity, the response at $10 \mathrm{kHz}$ shows a coefficient of linear regression above 0.84 while the fitting curve at $1 \mathrm{kHz}$ has a coefficient of linear regression below 0.73 . In fact, a better approach is to linearize the response by $\mathrm{RH}$ sections, defining two different curves according to the RH level (see Table 1). With respect to the hysteresis, the maximum error between the data recorded increasing and decreasing RH is about $200 \mathrm{fF}$ at $1 \mathrm{kHz}$ and about $50 \mathrm{fF}$ at $10 \mathrm{kHz}$. In both cases, the maximum error occurs at $60 \% \mathrm{RH}$.

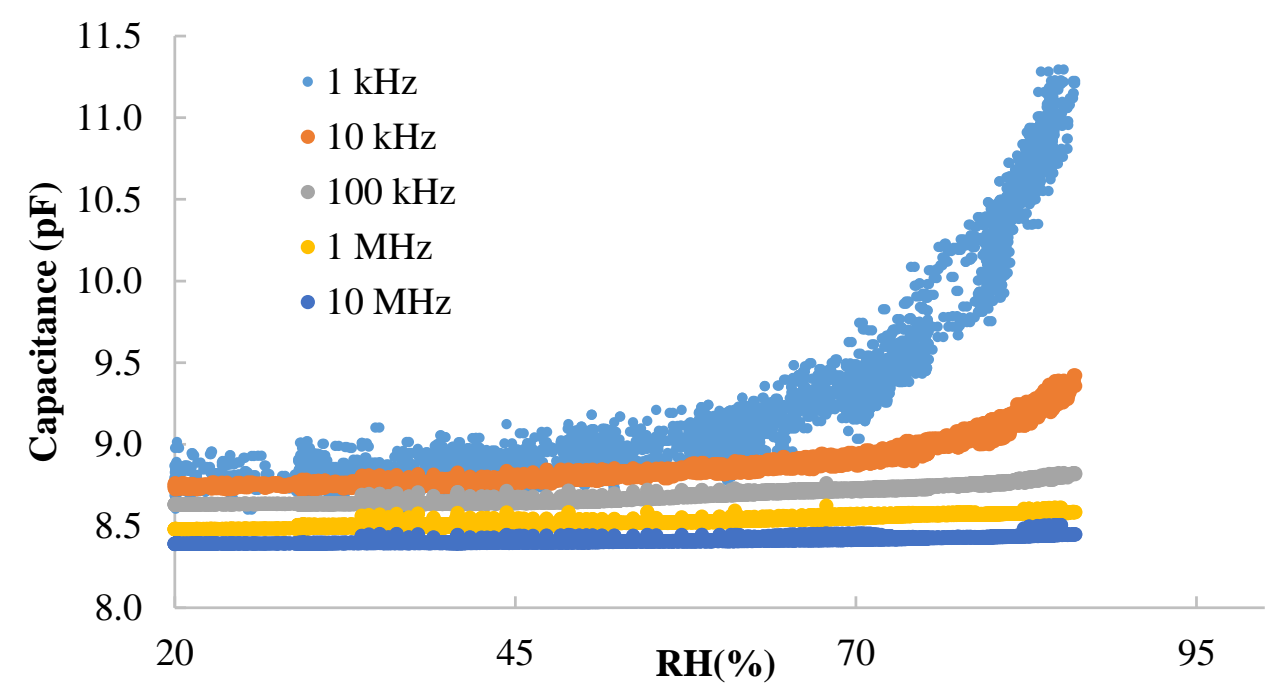

Figure 3. Capacitance vs. RH at different frequencies and $40^{\circ} \mathrm{C}$.

Looking at the calibration curves, they could be better fitted by two lines, one covering from $20 \%$ $\mathrm{RH}$ to $55 \% \mathrm{RH}$ and the other fitting line for higher RH values, see Table 1 . In fact, the sensitivity above $55 \% \mathrm{RH}$ is one order of magnitude higher than at low $\mathrm{RH}$ values. In the case of the curves for higher $\mathrm{RH}$ values, the sensitivity is about $70 \mathrm{fF} / \% \mathrm{RH}$ and $17 \mathrm{fF} / \% \mathrm{RH}$ at $1 \mathrm{kHz}$ and $10 \mathrm{kHz}$, respectively. It should be noted that the linear coefficient of these curves is between 0.90 and 0.95 , depending on the $\mathrm{RH}$ level and frequency of operation. Ideally, such coefficients should be higher than 0.99 . Nevertheless, although linearity is desirable for sensors, it is not crucial for their use. What is important is the fact that the sensors can discriminate RH values in the whole analyzed range. 


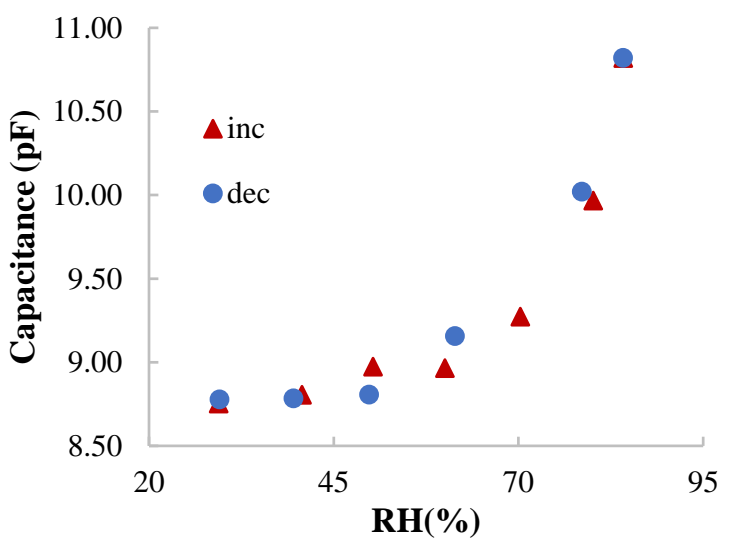

(a)

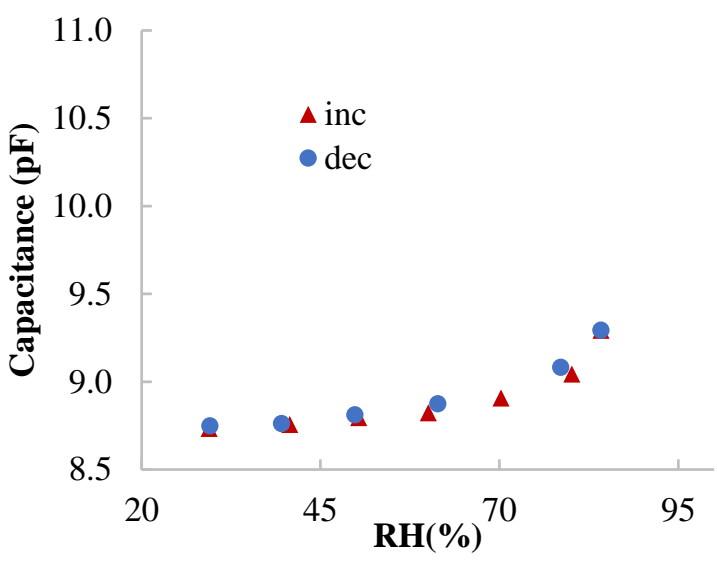

(b)

Figure 4. Calibration curves increasing and decreasing $\mathrm{RH}$ at $1 \mathrm{kHz}$ (a) and $10 \mathrm{kHz}$ (b). In both graphs, it is shown the responses when $\mathrm{RH}$ is increasing (inc) and decreasing (dec).

Table 1. Calibration curves extracted from Figure 4.

\begin{tabular}{ccc}
\hline Freq. & $\mathbf{R H}<\mathbf{5 5 \%}$ & $\mathbf{R H}>\mathbf{5 5 \%}$ \\
\hline \multirow{2}{*}{$1 \mathrm{kHz}$} & $\mathrm{C}(\mathrm{pF})=0.0047 \cdot \mathrm{RH}(\%)+8.6162$ & $\mathrm{C}(\mathrm{pF})=0.0696 \cdot \mathrm{RH}(\%)+4.9399$ \\
& $\mathrm{R}^{2}=0.9579$ & $\mathrm{R}^{2}=0.9050$ \\
\hline \multirow{2}{*}{$10 \mathrm{kHz}$} & $\mathrm{C}(\mathrm{pF})=0.0028 \cdot \mathrm{RH}(\%)+8.6542$ & $\mathrm{C}(\mathrm{pF})=0.0169 \cdot \mathrm{RH}(\%)+7.7843$ \\
& $\mathrm{R}^{2}=0.9468$ & $\mathrm{R}^{2}=0.8995$ \\
\hline
\end{tabular}

The possible response mechanism of the synthesized Cdots can be explained with the properties of the characteristics of the surface of the nanoparticles. Previously, the polymer PEI has been used in the functionalization of graphene, introducing an electronic doping for example in carbon nanotubes [38]. PEI is known for its high hydrophilicity, which is why it has been used in humidity sensors. In said polymer, water molecules are adsorbed on PEI due to the basic nature of PEI's hydrogen bond and PEI amines partially protonate by donating protons [39-41].

Regarding the bending stress, we have tested the sensors over 100 bending cycles at $1 \mathrm{~mm}$ length and we found a variation in the capacitance below $0.5 \%$. The sensors were tested 6 months after its fabrication and first characterization tests, and they exhibit a variation of only $2 \%$.

Despite the sensitivity found for this Cdots-based sensor is in the range of few $\mathrm{fF} / \% \mathrm{RH}$, other printed capacitive RH sensors, which used different sensing layers, exhibited sensitivities in the same range [21,42]. For example, Molina-Lopez described a inkjet printed capacitive sensor with cellulose acetate butyrate $(\mathrm{CAB})$ as sensing material with a sensitivity of $2.36 \mathrm{fF} / \% \mathrm{RH}$ [42]. Moreover, in this work, we employed screen printing for the IDE definition, which provides a worse spatial resolution than other printing techniques such as inkjet printing. This poorer resolution directly affects the sensitivity because the fingers of the IDE structure cannot be defined as closer as with other technologies. However, screen printing results in a faster process, being closer to large-scale manufacturing.

\subsection{Response to Temperature}

The most interfering factor in humidity sensors is temperature. In this regard, we have analyzed its influence in our DUT, varying the temperature from 20 to $70{ }^{\circ} \mathrm{C}$. Notice that the sensors could not be used upon $115^{\circ} \mathrm{C}$ because of the glass transition point of the employed substrate. Figure 5 shows the capacitance over temperature for different frequencies at 60\% RH (Figure 5a) and 40\% RH (Figure 5b). It can be seen how there is a significant thermal drift in both cases, although it is slightly lower at higher RH values. 


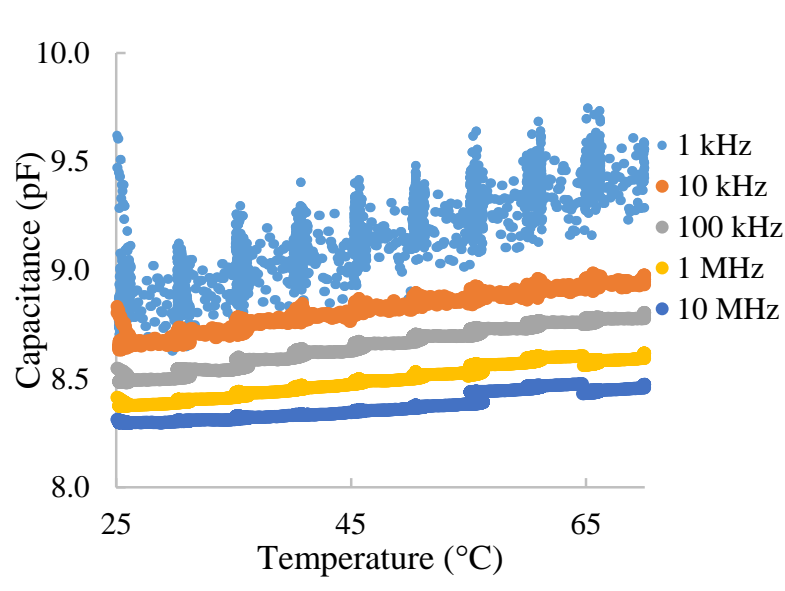

(a)

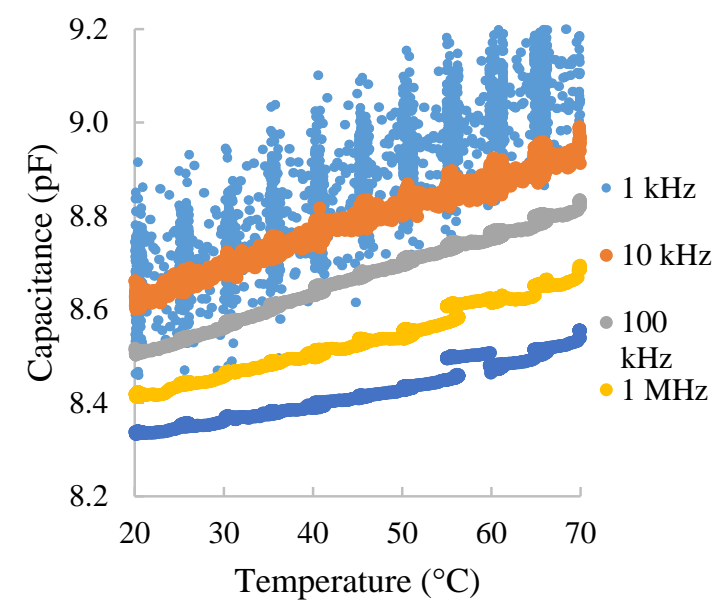

(b)

Figure 5. Capacitance vs. temperature at different frequencies and (a) $60 \% \mathrm{RH}$ and (b) $40 \% \mathrm{RH}$.

Finally, we have calculated the sensitivity to RH and the thermal drift of the sensor at the different frequencies, $\mathrm{S}_{\mathrm{RH}}$ and $\mathrm{S}_{\mathrm{T}}(\mathrm{f})$, respectively using Equations (1) and (2).

$$
\begin{gathered}
\mathrm{S}_{\mathrm{RH}}=\frac{\partial \mathrm{C}_{\mathrm{T}=\mathrm{cte}}(\mathrm{RH})}{\partial \mathrm{RH}} . \\
\mathrm{S}_{\mathrm{T}}=\frac{\partial \mathrm{C}_{\mathrm{RH}=\mathrm{cte}}(\mathrm{T})}{\partial \mathrm{RH}} .
\end{gathered}
$$

Figure 6 presents the calculated sensitivities. The dependency with respect $\mathrm{RH}$ is 4 times higher at $1 \mathrm{kHz}$ and 1.5 times at $10 \mathrm{kHz}$ than the one to temperature whereas at higher frequencies there is almost no dependency towards RH but the thermal drift cannot be neglected (even at $10 \mathrm{MHz}$ the variation is more than $3 \mathrm{fF} /{ }^{\circ} \mathrm{C}$ ). In fact, $\mathrm{RH}$ sensors are commonly affected by temperature [43], requiring thermal compensation [44-46]. This could be exploited as self-thermal compensated RH sensor by measuring at higher frequencies (above $1 \mathrm{MHz}$ ) the temperature value and using it to compensate the RH value obtained at lower frequencies (below $100 \mathrm{kHz}$ ).

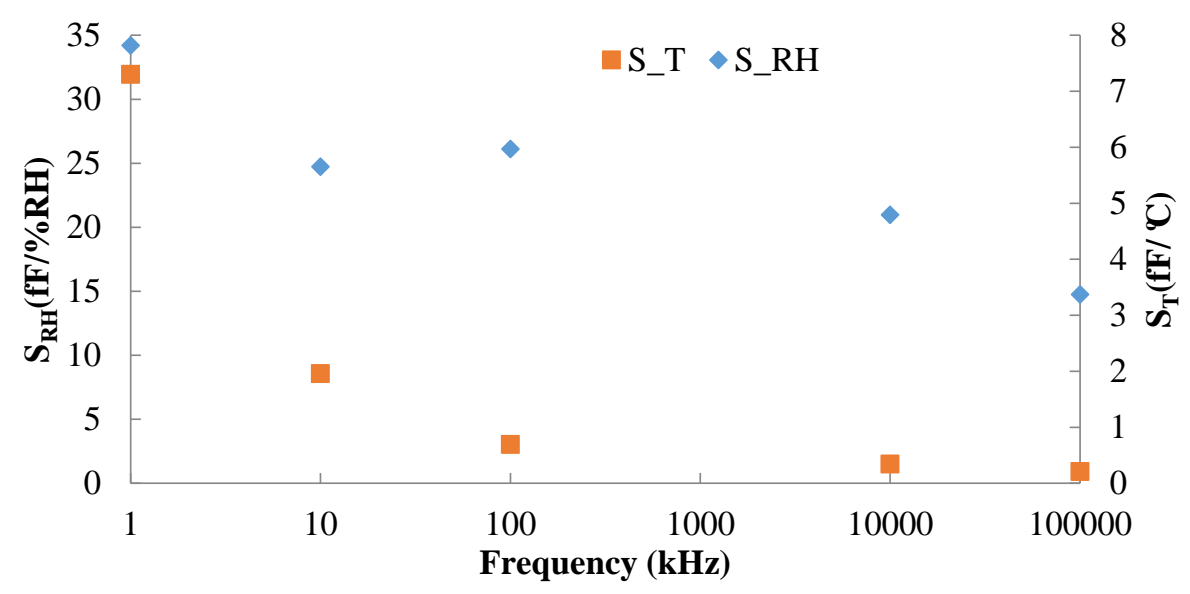

Figure 6. Sensitivity to $\mathrm{RH}\left(\right.$ at $40{ }^{\circ} \mathrm{C}$ ) and thermal (at $60 \% \mathrm{RH}$ ) sensitivity over frequency.

\section{Conclusions}

Carbon dots materials have been studied for sensing devices implementations in IDE for their use for humidity sensors. Different to previous developed Cdots sensors for moisture content detection, our sensors present a capacitive response, which results in a lower power consumption and faster 
response in comparison with resistive behavior [47]. Furthermore, the sensors are fabricated by printing techniques on a flexible substrate, providing more interesting features, such as pervasiveness, and light-weight and cost-effective devices. Cdots can be used as sensing layer in this kind of devices, although an exhaustive characterization on frequency is mandatory.

The fabricated devices show a capacitive behavior with about $8.7 \mathrm{pF}$ measured at $100 \mathrm{kHz}$ and room conditions. The highest response towards $\mathrm{RH}$ is found at the lowest frequency. Above $100 \mathrm{kHz}$ the capacitance changes less than $100 \mathrm{fF}$ for the analyzed $\mathrm{RH}$ range. In terms of absolute response, the capacitance varies $2 \mathrm{pF}$ at $1 \mathrm{kHz}$ and $0.6 \mathrm{pF}$ at $10 \mathrm{kHz}$ from $20 \%$ to $90 \% \mathrm{RH}$.

Moreover, from this study, a method of temperature compensation could be used without tending an extra temperature sensor: self-compensated humidity sensor. To achieve that, the temperature will be measured at frequencies above $1 \mathrm{MHz}$, and this reading of the temperature will be employed to compensate the RH value obtained at frequencies below $100 \mathrm{kHz}$.

Author Contributions: Conceptualization, A.S.-C. and D.P.M.; Methodology, A.R.; Investigation, F.M. and J.F.S.; Resources, N.R.; Writing-original draft preparation, A.R.; Writing-review and editing, A.S.-C., A.L.-F., and D.P.M.; Supervision, L.F.C.-V. All authors have read and agreed to the published version of the manuscript.

Funding: This work has been supported by the European Commission through the fellowship H2020-MSCA-IF-2017794885-SELFSENS.

Conflicts of Interest: The authors declare no conflict of interest.

\section{References}

1. Sullivan, F. Global Humidity and Moisture Sensors Market Forecast to 2023, Industry Analysis, Market Share \& Size. Available online: https://www.researchandmarkets.com/research/2bv5z2/global_humidity (accessed on 14 November 2019).

2. Bridgeman, D.; Corral, J.; Quach, A.; Xian, X.; Forzani, E. Colorimetric humidity sensor based on liquid composite materials for the monitoring of food and pharmaceuticals. Langmuir 2014, 30, 10785-10791. [CrossRef] [PubMed]

3. Bibi, F.; Guillaume, C.; Gontard, N.; Sorli, B. A review: Rfid technology having sensing aptitudes for food industry and their contribution to tracking and monitoring of food products. Trends Food Sci. Technol. 2017, 62, 91-103. [CrossRef]

4. Trung, T.Q.; Ramasundaram, S.; Lee, N.-E. Transparent, stretchable, and rapid-response humidity sensor for body-attachable wearable electronics. Nano Res. 2017, 10, 2021-2033. [CrossRef]

5. Salvo, P.; Di Francesco, F.; Costanzo, D.; Ferrari, C.; Trivella, M.G.; De Rossi, D. A wearable sensor for measuring sweat rate. IEEE Sens. J. 2010, 10, 1557-1558. [CrossRef]

6. Kang, U.; Wise, K.D. A high-speed capacitive humidity sensor with on-chip thermal reset. IEEE Trans. Electron. Devices 2000, 47, 702-710. [CrossRef]

7. Kim, J.-H.; Hong, S.-M.; Moon, B.-M.; Kim, K. High-performance capacitive humidity sensor with novel electrode and polyimide layer based on mems technology. Microsyst. Technol. 2010, 16, 2017-2021. [CrossRef]

8. Tetelin, A.; Pellet, C. Modeling and optimization of a fast response capacitive humidity sensor. IEEE Sens. J. 2006, 6, 714-720. [CrossRef]

9. Falco, A.; Loghin, F.C.; Becherer, M.; Lugli, P.; Salmerón, J.F.; Rivadeneyra, A. Low-cost gas sensing: Dynamic self-compensation of humidity in cnt-based devices. ACS Sens. 2019, 4, 3141-3146. [CrossRef]

10. Seco, J.M.; San, S.E.; Cepeda, J.; Biel, B.; Salinas-Castillo, A.; Fernández, B.; Morales, D.P.; Bobinger, M.; Gómez-Ruiz, S.; Loghin, F.C. A potassium metal-organic framework based on perylene-3, 4, 9, 10-tetracarboxylate as sensing layer for humidity actuators. Sci. Rep. 2018, 8, 1-10. [CrossRef]

11. Rivadeneyra, A.; Fernández-Salmerón, J.; Agudo-Acemel, M.; López-Villanueva, J.A.; Capitán-Vallvey, L.F.; Palma, A.J. Hybrid printed device for simultaneous vapors sensing. IEEE Sens. J. 2016, 16, 8501-8508.

12. Borini, S.; White, R.; Wei, D.; Astley, M.; Haque, S.; Spigone, E.; Harris, N.; Kivioja, J.; Ryhanen, T. Ultrafast graphene oxide humidity sensors. ACS Nano 2013, 7, 11166-11173. [CrossRef] [PubMed]

13. Bi, H.; Yin, K.; Xie, X.; Ji, J.; Wan, S.; Sun, L.; Terrones, M.; Dresselhaus, M.S. Ultrahigh humidity sensitivity of graphene oxide. Sci. Rep. 2013, 3, 1-7. [CrossRef] [PubMed] 
14. Schütt, F.; Postica, V.; Adelung, R.; Lupan, O. Single and networked zno-cnt hybrid tetrapods for selective room-temperature high-performance ammonia sensors. ACS Appl. Mater. Interfaces 2017, 9, 23107-23118. [CrossRef] [PubMed]

15. Abdulla, S.; Mathew, T.L.; Pullithadathil, B. Highly sensitive, room temperature gas sensor based on polyaniline-multiwalled carbon nanotubes (pani/mwcnts) nanocomposite for trace-level ammonia detection. Sens. Actuators B Chem. 2015, 221, 1523-1534. [CrossRef]

16. Young, S.-J.; Lin, Z.-D. Sensing performance of carbon dioxide gas sensors with carbon nanotubes on plastic substrate. ECS J. Solid State Sci. Technol. 2017, 6, M72-M74. [CrossRef]

17. Cagatay, E.; Falco, A.; Abdellah, A.; Lugli, P. Carbon nanotube based temperature sensors fabricated by large-scale spray deposition. In Proceedings of the 2014 10th Conference on Ph.D. Research in Microelectronics and Electronics (PRIME), Grenoble, France, 30 June-3 July 2014; pp. 1-4.

18. Romero, F.; Salinas-Castillo, A.; Rivadeneyra, A.; Albrecht, A.; Godoy, A.; Morales, D.P.; Rodriguez, N. In-depth study of laser ablation of kapton polyimide for flexible conductive substrates. Nanomaterials 2018, 8, 517. [CrossRef] [PubMed]

19. Jung, D.; Kim, J.; Lee, G.S. Enhanced humidity-sensing response of metal oxide coated carbon nanotube. Sens. Actuators A Phys. 2015, 223, 11-17. [CrossRef]

20. Star, A.; Joshi, V.; Skarupo, S.; Thomas, D.; Gabriel, J.-C.P. Gas sensor array based on metal-decorated carbon nanotubes. J. Phys. Chem. B 2006, 110, 21014-21020. [CrossRef]

21. Rivadeneyra, A.; Fernández-Salmerón, J.; Agudo-Acemel, M.; López-Villanueva, J.A.; Capitan-Vallvey, L.F.; Palma, A.J. Printed electrodes structures as capacitive humidity sensors: A comparison. Sens. Actuators A Phys. 2016, 244, 56-65. [CrossRef]

22. Abdelhalim, A.; Winkler, M.; Loghin, F.; Zeiser, C.; Lugli, P.; Abdellah, A. Highly sensitive and selective carbon nanotube-based gas sensor arrays functionalized with different metallic nanoparticles. Sens. Actuators B Chem. 2015, 220, 1288-1296. [CrossRef]

23. Abdelhalim, A.; Abdellah, A.; Scarpa, G.; Lugli, P. Metallic nanoparticles functionalizing carbon nanotube networks for gas sensing applications. Nanotechnology 2014, 25, 055208. [CrossRef]

24. Liu, W.; Li, C.; Ren, Y.; Sun, X.; Pan, W.; Li, Y.; Wang, J.; Wang, W. Carbon dots: Surface engineering and applications. J. Mater. Chem. B 2016, 4, 5772-5788. [CrossRef] [PubMed]

25. Xi, N.; Lai, K. Nano Optoelectronic Sensors and Devices: Nanophotonics from Design to Manufacturing; William Andrew: Waltham, MA, USA, 2011.

26. Gao, J.; Zhu, M.; Huang, H.; Liu, Y.; Kang, Z. Advances, challenges and promises of carbon dots. Inorg. Chem. Front. 2017, 4, 1963-1986. [CrossRef]

27. Zhang, X.; Ming, H.; Liu, R.; Han, X.; Kang, Z.; Liu, Y.; Zhang, Y. Highly sensitive humidity sensing properties of carbon quantum dots films. Mater. Res. Bull. 2013, 48, 790-794. [CrossRef]

28. Kalita, H.; Palaparthy, V.S.; Baghini, M.S.; Aslam, M. Graphene quantum dot soil moisture sensor. Sens. Actuators B Chem. 2016, 233, 582-590. [CrossRef]

29. Alizadeh, T.; Shokri, M. A new humidity sensor based upon graphene quantum dots prepared via carbonization of citric acid. Sens. Actuators B Chem. 2016, 222, 728-734. [CrossRef]

30. Columbus, L. Roundup of Internet of Things Forecasts and Market Estimates. 2016. Available online: https: //www.forbes.com/sites/louiscolumbus/2016/11/27/roundup-of-internet-of-things-forecasts-and-marketestimates-2016/\#75dee127292d (accessed on 31 July 2020).

31. Suganuma, K. Introduction to Printed Electronics; Springer Science \& Business Media: New York, NY, USA, 2014; Volume 74.

32. Mattana, G.; Briand, D. Recent advances in printed sensors on foil. Mater. Today 2016, 19, 88-99. [CrossRef]

33. Rivadeneyra, A.; Fernández-Salmerón, J.; Agudo, M.; López-Villanueva, J.; Capitan-Vallvey, L.; Palma, A. Design and characterization of a low thermal drift capacitive humidity sensor by inkjet-printing. Sens. Actuators B Chem. 2014, 195, 123-131. [CrossRef]

34. Salinas-Castillo, A.; Morales, D.P.; Lapresta-Fernández, A.; Ariza-Avidad, M.; Castillo, E.; Martínez-Olmos, A.; Palma, A.J.; Capitan-Vallvey, L.F. Evaluation of a reconfigurable portable instrument for copper determination based on luminescent carbon dots. Anal. Bioanal. Chem. 2016, 408, 3013-3020. [CrossRef] 
35. Salinas-Castillo, A.; Ariza-Avidad, M.; Pritz, C.; Camprubí-Robles, M.; Fernández, B.; Ruedas-Rama, M.J.; Megia-Fernández, A.; Lapresta-Fernández, A.; Santoyo-Gonzalez, F.; Schrott-Fischer, A. Carbon dots for copper detection with down and upconversion fluorescent properties as excitation sources. Chem. Commun. 2013, 49, 1103-1105. [CrossRef]

36. Bobinger, M.R.; Romero, F.J.; Salinas-Castillo, A.; Becherer, M.; Lugli, P.; Morales, D.P.; Rodríguez, N.; Rivadeneyra, A. Flexible and robust laser-induced graphene heaters photothermally scribed on bare polyimide substrates. Carbon 2019, 144, 116-126. [CrossRef]

37. Rivadeneyra, A.; Salmerón, J.F.; Agudo-Acemel, M.; Capitan-Vallvey, L.F.; López-Villanueva, J.A.; Palma, A.J. Asymmetric enhanced surface interdigitated electrode capacitor with two out-of-plane electrodes. Sens. Actuators B Chem. 2018, 254, 588-596. [CrossRef]

38. Qi, P.; Vermesh, O.; Grecu, M.; Javey, A.; Wang, Q.; Dai, H.; Peng, S.; Cho, K. Toward large arrays of multiplex functionalized carbon nanotube sensors for highly sensitive and selective molecular detection. Nano Lett. 2003, 3, 347-351. [CrossRef]

39. Chachulski, B.; Gebicki, J.; Jasinski, G.; Jasinski, P.; Nowakowski, A. Properties of a polyethyleneimine-based sensor for measuring medium and high relative humidity. Meas. Sci. Technol. 2005, 17, 12. [CrossRef]

40. Zajt, T.; Jasinski, G.; Chachulski, B. Electrical properties of polymer humidity sensor based on polyethyleneimine. In Optoelectronic and Electronic Sensors V, Proceeding of the International Society for Optics and Photonics, Rzeszow, Poland, 5-8 June 2002; SPIE: Washington, DC, USA, 2003; pp. 130-137.

41. Ben, A.Z.; Zhang, K.; Baillargeat, D.; Zhang, Q. Enhancement of humidity sensitivity of graphene through functionalization with polyethylenimine. Appl. Phys. Lett. 2015, 107, 134102.

42. Molina-Lopez, F.; Briand, D.; de Rooij, N. All additive inkjet printed humidity sensors on plastic substrate. Sens. Actuators B Chem. 2012, 166, 212-222. [CrossRef]

43. Bull, K. Methods of accurately measuring capacitive rh sensors. In Proceedings of the 5th International Symposium on Humidity and Moisture-ISHM, Rio de Janeiro, Brazil, 2-5 May 2006.

44. Courbat, J.; Kim, Y.; Briand, D.; de Rooij, N. Inkjet printing on paper for the realization of humidity and temperature sensors. In Proceedings of the 2011 16th International Solid-State Sensors, Actuators and Microsystems Conference (TRANSDUCERS), Beijing, China, 5-9 June 2011; pp. 1356-1359.

45. Molina-Lopez, F.; Quintero, A.V.; Mattana, G.; Briand, D.; de Rooij, N. Large-area compatible fabrication and encapsulation of inkjet-printed humidity sensors on flexible foils with integrated thermal compensation. J. Micromech. Microeng. 2013, 23, 025012. [CrossRef]

46. Oprea, A.; Courbat, J.; Bârsan, N.; Briand, D.; De Rooij, N.; Weimar, U. Temperature, humidity and gas sensors integrated on plastic foil for low power applications. Sens. Actuators B Chem. 2009, 140, 227-232. [CrossRef]

47. Rivadeneyra, A.; López-Villanueva, J.A. Recent advances in printed capacitive sensors. Micromachines 2020, 11, 367. [CrossRef]

Publisher's Note: MDPI stays neutral with regard to jurisdictional claims in published maps and institutional affiliations.

(C) 2020 by the authors. Licensee MDPI, Basel, Switzerland. This article is an open access article distributed under the terms and conditions of the Creative Commons Attribution (CC BY) license (http://creativecommons.org/licenses/by/4.0/). 